\title{
On Estimation of the CES Production Function - Revisited
}

\author{
Henningsen, Arne; Henningsen, Geraldine
}

Published in:

Economics Letters

Link to article, DOI:

10.1016/j.econlet.2011.12.007

Publication date:

2012

Document Version

Early version, also known as pre-print

Link back to DTU Orbit

Citation (APA):

Henningsen, A., \& Henningsen, G. (2012). On Estimation of the CES Production Function - Revisited.

Economics Letters, 115(1), 67-69. https://doi.org/10.1016/j.econlet.2011.12.007

\section{General rights}

Copyright and moral rights for the publications made accessible in the public portal are retained by the authors and/or other copyright owners and it is a condition of accessing publications that users recognise and abide by the legal requirements associated with these rights.

- Users may download and print one copy of any publication from the public portal for the purpose of private study or research.

- You may not further distribute the material or use it for any profit-making activity or commercial gain

- You may freely distribute the URL identifying the publication in the public portal

If you believe that this document breaches copyright please contact us providing details, and we will remove access to the work immediately and investigate your claim. 


\section{Accepted Manuscript}

On estimation of the CES production function—Revisited

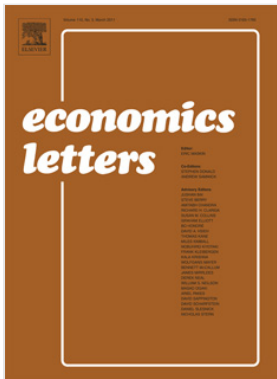

Arne Henningsen, Géraldine Henningsen

PII:

S0165-1765(11)00518-0

DOI:

10.1016/j.econlet.2011.12.007

Reference: $\quad$ ECOLET 5077

To appear in: Economics Letters

Received date: 8 August 2011

Revised date: 29 November 2011

Accepted date: 3 December 2011

Please cite this article as: Henningsen, A., Henningsen, G., On estimation of the CES

production function—Revisited. Economics Letters (2011), doi:10.1016/j.econlet.2011.12.007

This is a PDF file of an unedited manuscript that has been accepted for publication. As a service to our customers we are providing this early version of the manuscript. The manuscript will undergo copyediting, typesetting, and review of the resulting proof before it is published in its final form. Please note that during the production process errors may be discovered which could affect the content, and all legal disclaimers that apply to the journal pertain. 
Highlights

- We propose three solutions to avoid serious problems when estimating CES functions.

- Removing discontinuities by using the limits of the CES function and its derivatives.

- Circumventing large rounding errors by local linear approximations.

- Handling ill-behaved objective functions by a multi-dimensional grid search. 


\title{
On Estimation of the CES Production Function-Revisited ${ }^{\text {th }}$
}

\author{
Arne Henningsen ${ }^{\mathrm{a}, *}$, Géraldine Henningsen ${ }^{\mathrm{b}}$ \\ ${ }^{a}$ Institute of Food and Resource Economics, University of Copenhagen, Rolighedsvej 25, \\ 1958 Frederiksberg C, Denmark, Phone: +45-353322 74, Fax: +45-35336801 \\ ${ }^{b}$ Systems Analysis Division, Ris $\varnothing$ National Laboratory for Sustainable Energy, Technical University of \\ Denmark, Frederiksborgvej 399, P.O. Box 49, Building 110, 4000 Roskilde, Denmark
}

\begin{abstract}
Estimation of the non-linear Constant Elasticity of Scale (CES) function is generally considered problematic due to convergence problems and unstable and/or meaningless results. These problems often arise from a non-smooth objective function with large flat areas, the discontinuity of the CES function where the elasticity of substitution is one, and possibly significant rounding errors where the elasticity of substitution is close to one. We suggest three (combinable) solutions that alleviate these problems and improve the reliability and stability of the results.
\end{abstract}

JEL classification: C13, C51, D22, E23

Keywords: Constant Elasticity of Substitution, CES function, Estimation, Non-linear Least Squares

\section{Introduction}

The Constant Elasticity of Substitution (CES) function ${ }^{1}$

$$
y=\gamma\left(\delta x_{1}^{-\rho}+(1-\delta) x_{2}^{-\rho}\right)^{-\frac{\nu}{\rho}}
$$

was developed by the Stanford group (Arrow et al., 1961) to alleviate restrictive assumptions implied by the Cobb-Douglas function. Furthermore, nested CES functions have been developed to model more than two inputs in a flexible way. Their general

\footnotetext{
Senior authorship is shared equally.

* Corresponding author

Email addresses: arhe@life.ku.dk (Arne Henningsen), gehe@risoe.dtu.dk (Géraldine Henningsen)

${ }^{1}$ Variable $y$ is the output quantity, $x_{1}$ and $x_{2}$ are the input quantities, and $\gamma, \delta, \rho$, and $\nu$ are parameters, where $\gamma \in(0, \infty)$ determines the productivity, $\delta \in[0,1]$ determines the optimal distribution of the inputs, $\rho \in[-1,0) \cup(0, \infty)$ determines the (constant) elasticity of substitution, which is $\sigma=$ $1 /(1+\rho)$, and $\nu \in(0, \infty)$ is equal to the elasticity of scale.
} 
specification is ${ }^{2}$

$$
y=\gamma\left(\sum_{i=1}^{n} \delta_{i} z_{i}^{\rho / \rho_{i}}\right)^{-\nu / \rho} \text { with } z_{i}=\sum_{j=1}^{n_{i}} \delta_{j, i} x_{j, i}^{-\rho_{i}} \forall i=1, \ldots, n .
$$

Recently CES functions have gained popularity mainly in macroeconomic programming models, particularly in the areas of economic growth (e.g. Papageorgiou and Saam, 2008), international trade (e.g. Lloyd and MacLaren, 2002), and energy economics (e.g. McFarland et al., 2004), but the parameters are usually guesstimated and calibrated rather than based on empirical evidence. This arises from the low popularity of CES functions in empirical work, which mostly results from serious problems inherent in the econometric estimation. As CES functions are non-linear and cannot be linearised, standard linear estimation methods cannot be applied. Conversely, the estimation of the non-linear CES function frequently performs poorly. The main reason for this is the surface of the objective function, which often has a tendency to large flat areas and local minima. Further problems are discontinuities of CES functions and considerable rounding errors at specific parameter values.

Although this paper concentrates on non-linear least squares estimations, the presented solutions can be applied regardless of whether the model is estimated in log or levels (see Sun et al., 2011); the applied estimation method (e.g. the Poisson pseudomaximum likelihood estimation, see Sun et al., 2011), and which extensions of the CES functions are used (e.g. Hicks neutral or factor augmented technical progress, see Klump et al., 2007).

Section 2 exemplifies these problems and presents solutions that result in more reliable estimation results. Section 3 concludes.

\section{Challenges when estimating the CES by non-linear least squares}

The two standard approaches to estimating the parameters of CES functions are the linear Taylor-series approximation developed by Kmenta (1967) and the non-linear least squares estimation. However, the applicability of the so-called Kmenta approximation is limited, because it cannot be used to linearise CES functions with more than two inputs (Hoff, 2004), whilst it only returns reliable results if $\rho$ is close to its point of approximation (i.e. zero, see Thursby and Lovell, 1978). Conversely, non-linear optimisation algorithms very often face convergence problems or return varying, unreliable, or economically meaningless parameter estimates.

\subsection{Removable discontinuities}

One problem of non-linear optimisation algorithms may be caused by the discontinuities of the CES function where at least one of the substitution parameters $\left(\rho, \rho_{1}\right.$, $\left.\ldots, \rho_{n}\right)$ is zero. However, as these discontinuities are "removable", we can make CES function continuous by calculating the output quantities at these discontinuities by the

\footnotetext{
${ }^{2}$ The inputs are subdivided into $n$ groups, where $n_{i}$ denotes the number of inputs in the $i$ th group and $x_{j, i}$ denotes the $j$ th input in the $i$ th group. This specification requires the normalisations $\sum_{i=1}^{n} \delta_{i}=1$ and $\sum_{j=1}^{n_{i}} \delta_{j, i}=1 \forall i=1, \ldots, n$.
} 
limits for the substitution parameters approaching zero. For the two-input CES function, this limit is:

$$
y=\gamma x_{1}^{\nu \delta} x_{2}^{\nu(1-\delta)} .
$$

The limits of the three-input and four-input nested CES functions for all possible combinations of substitution parameters approaching zero are given in Henningsen and Henningsen (2011a).

Making the CES function continuous also makes the sum of squared residuals - the objective function of the non-linear least-squares estimation-continuous so that optimisation routines are not misled at these discontinuities. Furthermore, by removing the discontinuities of the (analytical) gradients of the RSS regarding the coefficients in a similar way, gradient-based solvers are also undisturbed by the discontinuities.

\subsection{Rounding errors}

Rounding errors are unavoidable on digital computers, but they are usually negligible. However, given the construction of the CES function, rounding errors become larger when at least one of the substitution parameters $\left(\rho, \rho_{1}, \ldots, \rho_{n}\right)$ approaches zero. In this case, the calculation of the predicted output $\hat{y}$ becomes increasingly imprecise, because first very small (in absolute terms) exponents (e.g. $-\rho$ or $-\rho_{i}$ ), then very large (in absolute terms) exponents (e.g. $-\nu / \rho$ or $\rho / \rho_{i}$ ) are applied. The imprecise calculation of the predicted output $\hat{y}$ distorts the calculation of the sum of squared residuals $\left(R S S=\sum_{t=1}^{T}\left(y_{t}-\hat{y}_{t}\right)^{2}\right)$, which is the objective function of the non-linear least squares estimation (see left panel of figure 1). In absolute terms, these rounding errors are rather
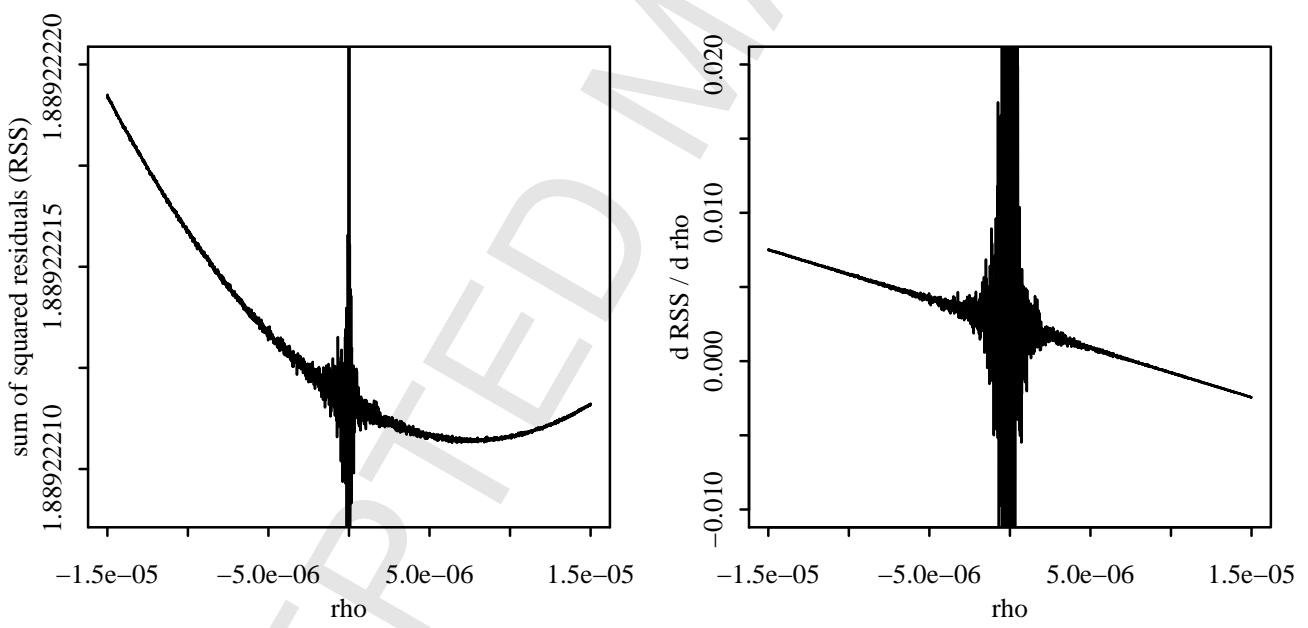

Figure 1: Rounding errors when $\rho$ is close to zero.

small (see scale of vertical axis), but given the extremely flat surface of the objective function, they can cause a significant deformation. The rounding errors in the calculations of the (analytical) gradients of the objective function with respect to the coefficientsparticularly with respect to the substitution parameters (e.g. $\partial R S S / \partial \rho$ ) - are even more 
severe (see right panel of figure 1). Hence, if the technology is close to a Cobb-Douglas function, i.e. with an elasticity of substitution close to one, estimating the CES function with non-linear optimisation algorithms may be problematic, particularly when using gradient-based optimisation algorithms.

To avoid a potentially imprecise calculation of the output of the two-input CES function, which would lead to an imprecise calculation of the sum of squared residuals (RSS), we use a first-order Taylor series approximation at the point $\rho=0$ (i.e. the Kmenta approximation), if $\rho$ is close to zero (e.g. if $|\rho|<10^{-5}$ ):

$$
y=\gamma x_{1}^{\nu \delta} x_{2}^{\nu(1-\delta)} \exp \left(-0.5 \rho \nu \delta(1-\delta)\left(\ln x_{1}-\ln x_{2}\right)^{2}\right)
$$

Analogously, we use first-order Taylor series approximations to calculate the gradients of the RSS with respect to the coefficients (see Henningsen and Henningsen, 2011a) if $\rho$ is close to zero.

In case of nested CES functions, the derivations of the Taylor series approximations (particularly of the gradients) are extremely laborious and cumbersome. Therefore, we suggest use of linear interpolations to avoid rounding errors. We can calculate the output quantities for two different values of each substitution parameter that is close to zero, i.e. zero (using the formula for the limit of this parameter approaching zero) and a small positive or negative number that has the same sign as this substitution parameter, but that is large enough to avoid rounding errors (e.g. $\pm 10^{-5}$ ). Depending on the number of substitution parameters $\left(\rho, \rho_{1}, \ldots, \rho_{n}\right)$ that are close to zero, a one or multi-dimensional linear interpolation must be applied.

\subsection{Surface of the objective function}

The most dominant problem in the estimation of the CES function is the surface of the objective function, which often encounters non-convexity, local minima, rills, valleys, and extremely flat surfaces, e.g. around the minimum. Figure 2 demonstrates this problem for a three-input nested CES function (capital, labour, energy) ${ }^{3}$ by plotting the sum of squared residuals (RSS) depending on the substitution parameters $\rho$ and $\rho_{1}$ in a three dimensional plot. Using global optimisation algorithms can alleviate problems caused by non-convexity, local minima, rills, and valleys, but they are usually rather slow and do not alleviate the problem of flat surfaces. Therefore, we suggest using a grid search procedure, where a grid of values for the substitution parameters $\left(\rho, \rho_{1}, \ldots, \rho_{n}\right)$ is pre-selected and the remaining parameters are estimated by non-linear least-squares, whilst holding the substitution parameters constant at each combination of the pre-defined values. While two-input CES functions only require a one-dimensional grid search for different values of $\rho$, the grid search for nested CES functions can be multi-dimensional, because these functions have more than one substitution parameter. An example of the outcome of a two-dimensional grid search for the two substitution parameters of a three-input nested CES function ( $\rho$ and $\rho_{1}$ ) is given in figure 2 .

At the end of the grid search procedure, we select the values of the substitution parameters (and the corresponding estimates of the other parameters) that result in the smallest sum of squared residuals (RSS). These selected parameter estimates can be used

\footnotetext{
${ }^{3}$ Data is available in Kemfert (1998).
} 


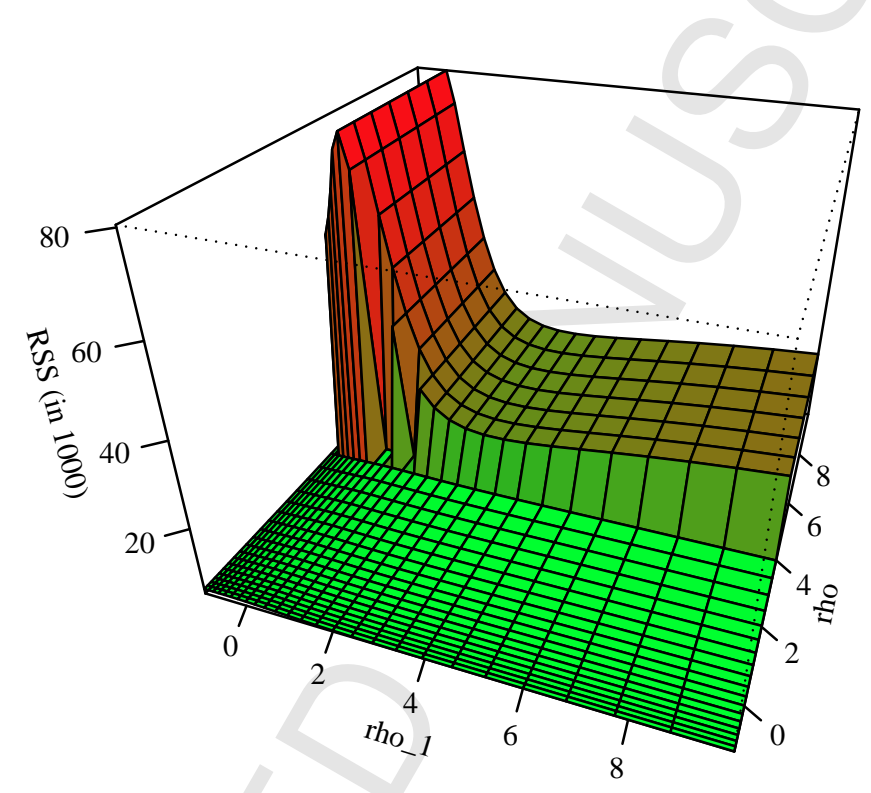

Figure 2: Minimum RSS for different combinations of $\rho_{1}$ and $\rho$. 
either directly or as starting values for a non-linear least-squares estimation, e.g. using a gradient-based optimisation routine. In the latter, substitution parameters that are between the grid points can also be estimated.

Removing the discontinuities of the CES function (see section 2.1) is particularly useful in combination with the grid search procedure, because it allows the inclusion of zeros as pre-selected values of the substitution parameters. Hence, the grid search can also include (nested) CES functions with the elasticities of substitution being unity. Furthermore, if the grid search procedure suggests a substitution parameter of zero and this is used as a starting value for subsequent estimation, the avoidance of rounding errors (see section 2.2) allows the optimisation routine to smoothly move away from zero.

\section{Conclusion}

We have distinguished three factors that often cause severe problems when estimating the CES function by non-linear optimisation algorithms and we have presented three different methods for alleviating or solving these problems: (i) removing discontinuities by using limits, (ii) removing rounding errors by using local linear approximations, and (iii) overcoming problems with an ill-behaved objective function by using a grid search procedure.

All three solutions have been implemented for non-linear least squares estimations in the R package "micEconCES" (Henningsen and Henningsen, 2011b). Henningsen and Henningsen (2011a) demonstrate, with two replication studies, that estimations that use these solutions produce stable and reliable results. We are optimistic that these tools will make the CES function more attractive to empirical economists. Furthermore, we hope that these tools will contribute to the reliability of economic programming models by increasing the availability of CES parameters that are based on empirical evidence rather than on guesstimation and calibration.

\section{Acknowledgements}

We are grateful to Frits Møller Andersen for encouraging us to write this paper and to him and an anonymous reviewer for valuable suggestions that helped us to improve this paper. Of course, all errors are the sole responsibility of the authors. 


\section{References}

Arrow, K. J., Chenery, B. H., Minhas, B. S., Solow, R. M., 1961. Capital-labor substitution and economic efficiency. The Review of Economics and Statistics 43 (3), 225-250.

URL http://www.jstor.org/stable/1927286

Henningsen, A., Henningsen, G., 2011a. Econometric estimation of the "Constant Elasticity of Substitution" function in R: Package micEconCES. FOI Working Paper 2011/9, Institute of Food and Resource Economics, University of Copenhagen.

URL http://EconPapers.repec.org/RePEc : foi : wpaper :2011_9

Henningsen, A., Henningsen, G., 2011b. micEconCES: Analysis with the Constant Elasticity of Scale (CES) Function. R package version 0.9, http://CRAN.R-project.org/package=micEconCES.

Hoff, A., 2004. The linear approximation of the CES function with $\mathrm{n}$ input variables. Marine Resource Economics 19, 295-306.

Kemfert, C., 1998. Estimated substitution elasticities of a nested CES production function approach for Germany. Energy Economics 20 (3), 249-264.

Klump, R., McAdam, P., Willman, A., 2007. Factor substitution and factor-augmenting technical progress in the United States: A normalized supply-side system approach. The Review of Economics and Statistics 89 (1), 183-192.

Kmenta, J., 1967. On estimation of the CES production function. International Economic Review 8, $180-189$.

Lloyd, P. J., MacLaren, D., 2002. Measures of trade openess using CGE analysis. Journal of Policy Modeling 24 (1), 67-81.

McFarland, J. R., Reilly, J. M., Herzog, H. J., 2004. Representing energy technologies in top-down economic models using bottom-up information. Energy Economics 26 (4), 685-707.

Papageorgiou, C., Saam, M., 2008. Two-level CES production technology in the Solow and Diamond growth models. Scandinavian Journal of Economics 110 (1), 119-143.

Sun, K., Henderson, D. J., Kumbhakar, S. C., 2011. Biases in approximating log production. Journal of Applied Econometrics 26 (4), 708-714.

Thursby, J. G., Lovell, C. A. K., 1978. An investigation of the Kmenta approximation to the CES function. International Economic Review 19 (2), 363-377. 